\title{
New System of Deprotection Step for the Hydroxide Radicals: Boron Trifluoride Etherate/Sodium Iodide
}

\author{
Yuqing Cao (Corresponding author) \\ College of Pharmacy, Hebei University, Baoding 071002, China \\ Tel: 86-189-3126-5805Ｅ-mail: coffeeyang2017@163.com \\ Xiaojun Yang \\ College of Pharmacy, Hebei University, Baoding-071002, China \\ Tel: 86-189-3126-5805Ｅ-mail: 303176856@qq.com \\ Dingxiang Du, Xiangtao Xu, Fangrui Song \& Liya Xu \\ College of Pharmacy, Hebei University \\ Baoding-071002, China
}

Received: March 14, 2011 Accepted: March 28, 2011 doi:10.5539/ijc.v3n3p113

\begin{abstract}
A new efficient method for dealkylation of ethers is reported. Ethers could transform into corresponding alcohols with boron trifluoride etherate and sodium iodide in acetonitrile after hydrolysis. This reaction can proceed at room temperature, and the yield is excellent. It's useful for deprotection process in organic synthesis.
\end{abstract}

Keywords: Boron trifluoride etherate, Sodium iodide, Deprotection, Ethers

\section{Introduction}

Hydroxide radical is very common in organic compounds, especially in nature extract, it could be transformed into ester, halogenated hydrocarbon, aldehydes, ketone, carboxylic acid and unsaturated hydrocarbon easily. It is necessary to protect the hydroxide radical from transforming when we do not want the hydroxide radical change into others. Alkylation of a hydroxyl moiety is regarded as one of the most effective protection methodologies. Firstly we change the hydroxide radical that we need to keep in final product into alkoxy, alkoxy behaves more inert than hydroxide radical. At last we need to process a deprotection step to return the hydroxide radical.

This method of protection and deprotection step is useful in both commercial and academic pursuits, such as natural product, fine chemical and pharmaceutical syntheses.

Many researchers bring forward their own means to accomplish this deprotection step since mid-20th centry. Lewis acids are usually used in the dealkylation reaction. The first reagent for dealkylation is $\mathrm{BBr}_{3}(\mathrm{Felix}, 1974$, p1427), but the usage of boron tribromide is limited for its intensive toxicity and explosibility when heated. Later people found some other dealkylation reagents, $\mathrm{Me}_{3} \mathrm{SiI}$ (Ho, 1976, p774) was used in this reaction commonly,

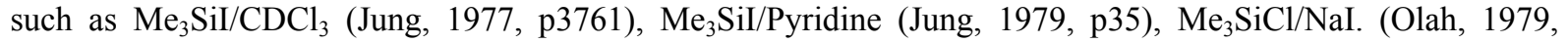
p1247).

Olivero (Olivero, 1995, p2497) found the electrochemistry means could transform some ethers into alcohols too. Except these reagents, $\mathrm{OsO}_{4} / \mathrm{N}$-methylmorpholine N-oxide (Mereyala, 1999, p11331), $\mathrm{NaBH}_{4} / \mathrm{THF}$ (Chary, 1999, p1223), $\mathrm{SmI}_{2} / \mathrm{THF}$ (Dahlen, 2003, p4085), $\mathrm{Pd}\left(\mathrm{PPh}_{3}\right)_{4} / \mathrm{MeOH}$ (Vutukuri, 2003, p1146) were test and verify to be feasible for some specially ethers. Shanthaveerappa (Boovanahalli, 2004, p3341) used the high nucleophilicity of bromideion in the form of ionic liquid, 1-n-butyl-3-methylimidazolium bromide, for the nucleophilic displacement of an alkyl group to regenerate a phenol from the corresponding aryl alkyl ether. This is a novel method and the yield is excellent, but the ionic liquid make the process too complicated, and the cost is too high.

Some ethers with special groups may need special reagent combination to complete the dealkylation process. $\mathrm{Ce}(\mathrm{OTf})_{4}$ could react with triphenylmethyl ethers and changed them into corresponding alcohols in mild 
conditions (Ali, 2001, p6805). Silyl ethers could changed into corresponding alcohols with sodium periodate in excellent yield (Mijuan, 2002, p8727). t-Butyldimethylsilyl ethers were efficiently and selectively changed into alcohols using silica supported sodium hydrogen sulfate $\left(\mathrm{NaHSO}_{4} \cdot \mathrm{SiO}_{2}\right)$ as a heterogeneous catalyst at room temperature in high yields (Biswanath, 2006, p5855). Shino found that the propargyl ethers could processed reductive deprotection reaction with $\mathrm{SmI}_{2}$-amine-water system (103 Shino, 2008, p5159). Farhad developed a method for direct oxidation of trimethylsilyl, tetrahydropyranyl and methoxymethyl ethers to their corresponding carbonyl compounds using trinitratocerium bromated supported on $\mathrm{NaHSO}_{4} \cdot \mathrm{H}_{2} \mathrm{O}$ under solvent-free conditions (Farhad, 2008, p676). 1-Decanethiol has been found to be an excellent reagent for the deprotection of aryl methyl ethers. A clear advantage of 1-decanethiol over the more commonly used thiols is the easy extraction of both the deprotecting reagent and the reaction byproducts into the aqueous phase, it could make the process more simple (Bhima, 2010, p3075).

We now report that a combination of boron trifluoride etherate/sodium iodide in acetonitrile, it could react with several kinds of ethers, the ethers could be changed into alcohols after a hydrolysis process. It is a mild, low-cost regents system, the yield is satisfying.

\section{Experimental}

\subsection{General}

The reaction is monitored with TLC (thin layer chromatography) and GC (gas chromatography). Melting points were determined on a microscopy apparatus (SGW X-4) and uncorrected. All the liquid parent materials were freshly distilled. The products were characterised by comparison of their melting points and boiling points with the literature values.

\subsection{General procedure}

To a stirred solution of ether $(10 \mathrm{mmol})$ and sodium iodide $(20 \mathrm{mmol}, 3.0 \mathrm{~g})$ in dry acetonitrile $(25 \mathrm{~mL})$ is added through a constant pressure funne boron trifluoride etherate $(20 \mathrm{mmol}, 5.42 \mathrm{~mL})$ smoothly and the mixture is stirred at room temperature. The mixture is then treated with saturated sodium hydrogen carbonate solution (25 $\mathrm{mL})$ and extracted with ether $(3 \times 10 \mathrm{~mL})$. The organic layer is washed with aqueous sodium thiosulfate solution $(20 \mathrm{~mL})$ followed by water $(50 \mathrm{~mL})$, dried with anhydrous sodium sulfate, and evaporated. The residue is then taken in ether $(25 \mathrm{~mL})$ and triturated. The ether layer is decanted from the precipitated salt; and distilled to yield the pure alcohol.

\section{Results and discussion}

\subsection{Choose the best experimental conditions}

We attempt to add the reagents at different scale and in different solvents, at last we found the best proportion of the raw is Ether: $\mathrm{NaI}_{\mathrm{B}} \mathrm{BF}_{3} \cdot \mathrm{Et}_{2} \mathrm{O}=1: 2: 2$, and the most suitable solvent is acetonitrile.

\subsection{Diversity analysis}

As the results show in table 1, we could see most of the ethers could convert to the corresponding alcohols or phenols in excellent yield, the aliphatic ethers need shorter time and the yield is higher than the aromatic ethers some ethers with special groups behave sluggishly comparatively.

The electron pair on the oxygen atom that attach with benzene ring direct could conjugate with the benzene ring, which would reduce the activity of this oxygen atom, make it hard to combine with Lewis acid BF3 (entry1-6, Table 1). An electron-withdrawing group on the benzene ring can reduce the activity of oxygen atom, make the reactions proceed more difficult (entry 2 , Table 1). The electron donating group on the benzene ring can make the reactions proceed easier (entry 3-4, Table 3).

\subsection{Selectivity of this reaction}

For the asymmetry ethers, the $\mathrm{C}-\mathrm{O}$ bond break selectively between the two side of oxygen atom. Generally speaking, the break order of $\mathrm{C}-\mathrm{O}$ bond from easy to hard is tertiary carbon, secondary carbon, primary carbon and aryl-carbon. Because the electron pair on the oxygen atom conjugate with the benzene ring, the $\mathrm{C}-\mathrm{O}$ bond between benzene and oxygen atom has some characteristic of double bond, so this bond break more difficult than the other one. This is why the product of entry 5 in table 1 is phenol, but not isoamylol.

The mechanism of this reaction we conjecture: firstly, $\mathrm{BF}_{3}$ combine with oxygen atom of ethers to generate a complex compound, then the iodine ion attack this complex compound, which led to the bond breaking between carbon and oxygen atom and generate a new compound A, A transform into alcohols or phenols through hydrolysis (Figure 2). 
In summary, a new method for the conversion of ethers into alcohols or phenols using boron trifluoride etherate-sodium iodide-acetonitrile system has been developed. This method is inexpensive, practical and with less pollution and easy work-up.

\section{References}

Ali, K.N. and Reza, F.A. (2001). Efficient and catalytic deprotection of triphenylmethyl ethers with $\mathrm{Ce}(\mathrm{OTf})_{4}$ Tetrahedron, 57, 6805.

Bhima, K., Ananta, S., Bapurao, S. and Samir, G. (2010). 1-Decanethiol, a new reagent for the odorless deprotection of aryl methyl ethers. Tetrahedron Letters, 51, 3075.

Biswanath, D., Ravinder, R.K. and Thirupathi, P. (2006). A simple, efficient and highly selective deprotection of t-butyldimethylsilyl ethers using silica supported sodium hydrogen sulfate as a heterogeneous catalyst. Tetrahedron Letters, 47, 5855.

Boovanahalli, S.K., Kim, D.W. and Chi, D.Y. (2004). Application of Ionic Liquid Halide Nucleophilicity for theleavage of Ethers: A Green Protocolforthe Regeneration of Phenolsfrom Ethers. J.Org.Chem., 10, 3341.

Chary, K.P., Mohan, G.H. and Iyengar, D.S. (1999). A Novel and Efficient Deoxygenation of Hetero Cyclic $\mathrm{N}$-Oxides Using $\mathrm{ZrCl}_{4} / \mathrm{NaBH}_{4}$. Chem.Lett., 28, 1223.

Dahlen, A., Sundgren, A., Lahmann, M., Oscarson, S. and Hilmersson, G. (2003). Selective cleavage of unsubstituted allyl ethers is provided by $\mathrm{SmI}_{2} / \mathrm{H}_{2} \mathrm{O} / \mathrm{i}-\mathrm{PrNH}_{2}$ in very good yields. Org.Lett., 5, 4085.

Farhad, S. and Saeideh, S. (2008). Efficient oxidative deprotection of trimethylsilyl, tetrahydropyranyl and methoxymethyl ethers under solvent-free conditions. Chinese Chemical Letters, 19, 676.

Felix, M. (1974). Cleavage of Protecting Groups with Boron Tribromide. J. Org. Chem., 39, 1427.

Ho, F.L., and Olah, G.A. (1976). Cleavage of Esters and Ethers with Iodotrimethylsilane. Angew. Chem.. Int. Ed., 15,774 .

Jung, M.E. and Lyster, M.A. (1977). Quantitative Dealkylation of Alkyl Ethers via Treatment with Trimethylsilyl Iodide. A New Method for Ether Hydrolysis. J. Org. Chem., 42, 3761.

Jung, M.E. and Lyster, M.A. (1979). Cleavage of methyl ethers with iodotrimethylsilane: cyclohexanol form cyclohexyl methyl ether. Organic Syntheses, 59, 35.

Mereyala, H.B., Gurrala, S.R. and Mohan, S.K. (1999). Study of metal and acid catalysed deprotection of propargyl ethers of alcohols via their allenyl ethers. Tetrahedron, 55, 11331.

Mijuan, W., Chun, L., Dali, Y. and Xiaotian, L. (2002). A mild and efficient approach for the deprotection of silyl ethers by sodium periodate. Tetrahedron Letters, 43, 8727.

Olah, G.A., Narang, S.C. and Gupta, B.G.B. (1979). Transformations with Chlorotrimethylsilane/Sodium Iodide, a Convenient in Situ Iodotrimethylsilane Reagent. J. Org. Chem., 44, 1247.

Olivero, S., Dunach, E. (1995). Nickel-catalysed electrochemical reductive deprotection of allyl ethers. Chem. Commun., 24, 2497.

Shino, M., Akiharu, U. and Yukishige, I. (2008). Reductive deprotection of propargyl ether by a SmI2-amine-water system and its application to polymer-supported oligosaccharide synthesis. Tetrahedron Letters, 49, 5159.

Vutukuri, D.R., Bharathi, P., Rajasekaran, K., Tran, M. and Thayumanavan, S. (2003). A Mild Deprotection Strategy for Allyl-Protecting Groups and Its Implications in Sequence Specific Dendrimer Synthesis. J. Org. Chem., 68, 1146. 
Table 1. Dealkylation of ethers

\begin{tabular}{|c|c|c|c|c|c|c|}
\hline \multirow{2}{*}{ Entry } & \multirow{2}{*}{ Substrate } & \multirow{2}{*}{ Product } & \multirow{2}{*}{ Time(h) } & \multirow{2}{*}{ Yield(\%) } & \multicolumn{2}{|c|}{ m.p. $\left({ }^{\circ} \mathrm{C}\right)$} \\
\hline & & & & & found & Reported $^{\mathrm{c}}$ \\
\hline 1 & & & 8 & 82 & $39-40^{\mathbf{a}}$ & $40-42$ \\
\hline 2 & & & 18 & 47 & $193-195^{\mathrm{a}}$ & 195 \\
\hline 3 & & & 8 & 85 & $30-32^{\mathrm{a}}$ & $32-34$ \\
\hline $4^{\mathrm{b}}$ & & & 8 & 87 & $170-172^{\mathrm{a}}$ & $172-175$ \\
\hline 5 & & & 18 & 38 & $39-40^{\mathbf{a}}$ & $40-42$ \\
\hline 6 & & & 8 & 83 & $121-123^{\mathrm{a}}$ & $122-123$ \\
\hline 7 & & & 6 & 89 & $157-159$ & $160-161$ \\
\hline 8 & & & 6 & 94 & $158-159$ & $160-161$ \\
\hline 9 & & & 6 & 95 & 137-139 & $139-140$ \\
\hline 10 & & & 6 & 95 & $38-40^{\mathrm{a}}$ & $38-40$ \\
\hline 11 & & & 6 & 94 & 103-104 & 104 \\
\hline 12 & & $\mathrm{C}_{7} \mathrm{H}_{15}-\mathrm{O}$ & 6 & 91 & 195-196 & 196 \\
\hline
\end{tabular}




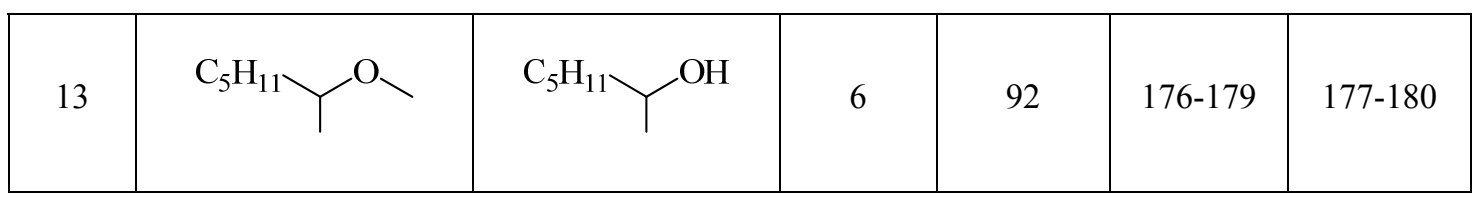

a. Determination of melting point.

b. The proportion of the reagent is ether: sodium iodide: boron trifluoride etherate $=1: 4: 4$.

c. The Merck Index, 2006, 13th Edn.

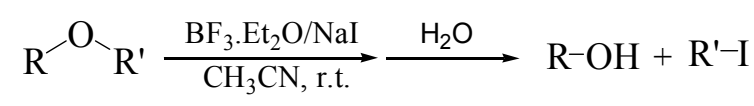

Figure 1. The reaction we design

$$
\begin{gathered}
\mathrm{R}^{-} \mathrm{R}_{\mathrm{R}^{\prime}} \stackrel{\mathrm{BF}_{3} \cdot \mathrm{Et}_{2} \mathrm{O} / \mathrm{NaI}}{\longrightarrow} \mathrm{R}-\mathrm{OBF}_{3}^{\ominus} \mathrm{Na}^{\oplus}+\mathrm{R}^{\prime}-\mathrm{I} \\
\mathrm{A} \\
\mathrm{H}_{2} \mathrm{O} \\
\mathrm{R}^{-} \mathrm{OH}
\end{gathered}
$$

Figure 2. The mechanism of this reaction 